\title{
VIDAS QUE SE CRUZAM NA PEDAGOGIA DO INSULTO: UMA ANÁLISE DAS VIVÊNCIAS ESCOLARES DE PESSOAS LGBTQIA
}

\author{
LIVES THAT CROSS IN THE INSULT PEDAGOGY: AN ANALYSIS OF \\ LGBTQIA PEOPLE'S SCHOOL LIVING
}

Isaias Batista de Oliveira Júnior

Doutor em Educação

Universidade Estadual de Maringá -UEM.

Maringá, PR, Brasil.

ibojunior@uem.br

Diego Raone Ferreira

Mestre em Enfermagem

Universidade Estadual de Maringá -UEM.

Maringá, PR, Brasil.

raonediego@gmail.com

\begin{abstract}
Resumo: A pedagogia do insulto atinge inúmeros estudantes LGBTQIA - Lésbicas, Gays, Bissexuais, Travestis, Transexuais, Transgêneros, Queer, Questionadores, Intersexos, Indecisos, Assexuados e Aliados, e representa estratégias que (re)produzem preconceitos, discriminações, violências e retirada de direitos elementares. Nesse sentido, questionamo-nos: de que maneira ela se manifesta nas vivências escolares, em desatendimento ao que a sociedade convencionou como norma? A fim de responder ao problema proposto, temos como objetivo analisar os relatos das vivências escolares de 118 participantes que se reconhecem como pessoas LGBTQIA. Para tanto, recorremos à análise de conteúdo sob o viés das seguintes categorias: interditos da diversidade sexual; des/contextualizando a LGBTQIAfobia; re/des/construindo estereótipos de gênero, as quais discutimos com base nos Estudos Culturais, nos estudos de gênero e na ordem do discurso. Concluímos que os padrões normalizadores adotados pela escola excluem aqueles considerados diferentes, impactando diretamente na esfera dos sentimentos, da dignidade e do desempenho escolar.
\end{abstract}

Palavras chave: diversidade sexual; escola; gênero; LGBTQIAfobia.

Abstract: The insult pedagogy affects many LGBTQIA students - Lesbian, Gay, Bisexual, Transvestite, Transgender, Queer, Questioner, Intersex, Undecided, Asexual and Allied, and represents strategies that (re)produce prejudice, discrimination, violence and withdrawal of rights elementary In this sense, we ask ourselves: in what way does it manifest itself in school experiences, in disregard of what society has agreed as a norm? In order to respond to the problem proposed, we aim to analyze the reports of the school experiences of 118 participants who recognize themselves as LGBTQIA people. To do so, we use content analysis under the bias of the following categories: prohibitions of sexual diversity; de / contextualizing LGBTQIAphobia; $\mathrm{re} / \mathrm{de} / \mathrm{constructing}$ gender stereotypes, which we discussed on the basis of Cultural Studies, gender studies and the order of discourse. We conclude that the standards adopted by the school exclude those considered as different, directly impacting the sphere of feelings, dignity and school performance.

Keywords: sexual diversity; school; genre; LGBTQIAphobia.

Para citar - (ABNT NBR 6023:2018)

OLIVEIRA JÚNIOR, Isaias Batista de; FERREIRA, Diego Raone. Vidas que se cruzam na pedagogia do insulto: uma análise das vivências escolares de pessoas LGBTQIA. Eccos - Revista Científica, São Paulo, n. 57, p. 1-18, e11337, abr./jun. 2021. Disponível em: https://doi.org/10.5585/eccos.n57.11337. 


\section{Introdução}

A pedagogia do insulto, termo cunhado por Junqueira (2013) e reiterado por Oliveira Júnior (2013), é um fenômeno social que atinge uma parcela significativa de jovens e adultos e representa estratégias que re/produzem preconceitos, discriminações, violências, bem como a retirada de direitos elementares.

Tais estratégias subversivas podem ser manifestas, dentre outras formas, "[...] em piadas, ridicularizações, brincadeiras, jogos, apelidos, insinuações, expressões desqualificantes e desumanizantes. Tratamentos preconceituosos, medidas discriminatórias, ofensas, constrangimentos, ameaças e agressões físicas ou verbais" (JUNQUEIRA, 2013, p. 484) que poderão ocorrer de forma sutil, como uma aparentemente inofensiva "brincadeira", ou ainda atingir situações extremas, como uma tentativa de homicídio.

Young (2009) aponta cinco faces do sistema opressor ora discutido: a exploração, que se caracteriza pela desigualdade de condições, permitindo que um grupo se beneficie direta ou indiretamente de outro; o desempoderamento, resultado da retirada e/ou descumprimento de direitos básicos; a violência sistêmica, composta por intensidades distintas que variam desde o ataque físico e/ou extermínio e discriminação social, até atitudes mais sutis, como a antilocução e/ou esquiva; o imperialismo cultural, que se ancora na adoção de determinada identidade como verdadeira, atribuindo o caráter desviante a todas aquelas contrárias a ela; a marginalização, reflexo das demais formas de opressão que pode se despontar na ausência de acesso às condições básicas de sobrevivência, tais como educação, emprego, saúde, moradia, dentre outras.

Quando esses atos de violência se manifestam num contexto privado como a escola, acabam por se traduzir em situações limites para pessoas Lésbicas, Gays, Bissexuais, Bigêneros, Travestis, Transexuais, Transgêneras, Queers, Questionadoras, Intersexos, Indecisas, Assexuadas e Aliadas - LGBTQIA, que vivem de diversas formas a LGBTQIAfobia, termo que empregaremos ao fazer referência ao aparato repressor definido por Young (2009).

Os atos de discriminação e exclusão ocorridos no ambiente escolar, incutidos no tratamento diferenciado de alunos com esse perfil, podem contribuir para que os mesmos incorporem tais preconceitos e pensem ser "realmente diferentes". Essa vigilância dos corpos sexuados resulta em sentimentos de angústia, opressão e medo e, por conseguinte, na evasão dos alunos LGBTQIA, não por inabilidade, mas uma expulsão compulsória, como define Bento (2011). 
Portanto, dar voz a essas pessoas não se faz apenas necessário, mas é um direito irrenunciável. Nesse sentido, justificamos o desenvolvimento deste estudo, pois determinadas posturas manifestas pelos sistemas de ensino interferem na realidade social, marcando, regulando e normatizando pessoas LGBTQIA e se desdobram na violação de direitos, ocasionando os mais variados prejuízos sociais ao inviabilizar o livre exercício dos diferentes modos de ser homem e mulher e de se viver a sexualidade.

Sendo assim, questionamo-nos: de que modo a pedagogia do insulto se manifesta nas vivências escolares de pessoas que estão em desatendimento ao que a sociedade convencionou como norma? Para responder ao problema proposto, objetivamos analisar os relatos das vivências escolares de pessoas Lésbicas, Gays, Bissexuais, Travestis, Transexuais, Transgêneras, Queer, Questionadoras, Intersexos, Indecisas, Assexuadas e Aliadas.

A fim de discutir os dados obtidos, recorremos à análise de conteúdo proposta por Bardin (2016), que se constrói segundo uma lógica específica, em que os participantes buscam apoiar seus discursos

[...] conservando-os (manifestando-os ou escondendo-os) [...] Sob a aparente desordem temática, trata-se de procurar a estruturação específica, a dinâmica pessoal, que, por detrás da torrente de palavras, rege o processo mental do entrevistado. Cada qual tem não só o seu registro de temas, mas também a sua própria maneira de (não) os mostrar (BARDIN, 2016, p.96).

Dessa forma, foram feitas inferências nos relatos de pessoas LGBTQIA como estratégia para compreendermos suas estruturações discursivas e como ferramenta para analisar suas vivências no contexto escolar, sob o viés das seguintes categorias de análise: interditos da diversidade sexual no contexto escolar (tabus, invisibilidade de estudantes LGBTQIA, implicações da pedagogia do insulto, processos de ridicularização); des/contextualização da LGBTQIAfobia (violência sistêmica e vigilância dos corpos); desconstrução de estereótipos de gênero (constituição da identidade de gênero, "heteroterrorismo", fragilidade da masculinidade), sob a perspectiva dos Estudos Culturais.

\section{Metodologia}

Adotamos a pesquisa descritiva e exploratória, uma vez que pretendemos descrever as características de uma determinada população, além de estabelecer as analogias entre variáveis, tais como a relação entre a diversidade sexual ou a identidade de gênero e o processo de escolarização de pessoas LGBTQIA. 
Antes, porém, é preciso ressaltar que o projeto que deu origem a este estudo foi submetido ao credenciamento junto ao Programa de Pós-Graduação em Educação para análise e, mediante aprovação para o Comitê Permanente de Ética em Pesquisa (COPEP) da Universidade Estadual de Maringá, autorizado sob a égide do $\mathrm{n}^{\circ}$. 2.698.275.

Após autorização do projeto disponibilizamos uma Webquest no Formulários Google, divulgando-o em redes sociais, como Facebook, $e$ aplicativos de conversas, como Messenger e WhatsApp. O questionário virtual foi estruturado em uma parte explicativa, composta pelo objetivo da pesquisa, apresentação, público alvo (pessoas que se reconhecessem LGBTQIA), solicitação de concordância com o Termo de Consentimento Livre e Esclarecido - TCLE, e questões que estruturaram os instrumentos, tais como: questionário sociodemográfico, Instrumento de Associação Livre de Palavras, (o qual não será apresentado neste momento) e questionário aberto.

Os indicadores sociodemográficos tiveram como pressuposto delinear o perfil dos participantes por meio de questões sobre gênero, idade, nível de escolaridade, formação acadêmica, religião, etc.

Do mesmo modo, as questões abertas possibilitaram aos participantes relatar sua trajetória pelo sistema de ensino como pessoas LGBTQIA, a partir da seguinte assertiva: faça um relato sobre sua trajetória escolar descrevendo aspectos relacionados à sua homossexualidade, bissexualidade e/ou transexualidade como, por exemplo, se algum/a professor/a abordou o assunto, a relação com os colegas de estudos, os eventos escolares, os casos de homofobia etc.

\section{Participantes}

Responderam à pesquisa 118 pessoas, sendo $71(60,1 \%)$ do sexo masculino e 47 $(39,8 \%)$ do sexo feminino. Quanto à orientação sexual, 13 (11\%) se consideram heterossexuais (vale ressaltar que esses indivíduos se reconheceram como transexuais), $17(14,4 \%)$ bissexuais, $84(71,1 \%)$ homossexuais e $03(3,3 \%)$ apontaram outras orientações, como a pansexualidade (indivíduo que aprecia e é atraído por todos os tipos de gêneros sexuais) e a assexualidade (que não tem ou aparentemente não tem vida sexual). As idades variaram entre 18 e 48 anos, sendo que a maioria, representada por 91 participantes $(77,1 \%)$, concentra-se na faixa etária de 18 a 35 anos.

No que se refere à formação acadêmica, a amostra foi composta por pessoas com nível superior incompleto 39 (33\%), superior completo 25 (21,1\%) e pós-graduação em nível latu e 
strictu sensu 74 (45,7\%). Os estudos em nível médio ou médio profissionalizante foram realizados por 84 participantes em escolas públicas $(71,1 \%), 31$ em escolas privadas $(26,2 \%)$ e 03 em outras instituições (2,5\%). Desses 118 entrevistados, em 27 deles $(22,8 \%)$ a atuação profissional se concentra na área da docência, 13 (11\%) na área da psicologia, 05 (4,2\%) na enfermagem e outros 44 (37,2\%) nas áreas de biomedicina, aviação, advocacia, fisioterapia, serviço público etc. Os outros 29 (24,5\%) se encontram em processo de formação universitária.

Tivemos a participação de sujeitos que residem em 13 Estados da Federação Brasileira, sendo a maioria do Paraná 62 (52,5\%), São Paulo 14 (11,8\%), Rio Grande do Sul 13 (11\%), Minas Gerais 08 (6,7\%), Rio de Janeiro 07 (5,9\%), e demais Estados como Amazonas, Bahia, Distrito Federal, Mato Grosso do Sul, Paraíba, Pernambuco, Santa Catarina e Sergipe, que totalizaram $14(11,8 \%)$,

\section{A sexualidade e a diversidade sexual: interditos escolares}

Junto com a família, a escola é considerada um agente primordial no processo de formação do ser social, já que possibilita o exercício de uma cidadania plena. Além disso, é tida como um espaço onde se cuida das novas gerações, uma instância mantenedora das aprendizagens e um lugar de direcionamento da juventude, em prol da preparação para o futuro. Portanto, ela tem dupla injunção: social - efetivada por meio da transmissão de determinada herança cultural às novas gerações; e individual - concretizada na aquisição de conhecimentos, formação de disposições, visões, habilidades e valores.

Nesse sentido, é necessária a inserção do debate de temas que possuam grande impacto e relevância na vida social e que insistentemente desafiem princípios democráticos e éticos por meio da regulação e manutenção de injustificáveis e distintos prejuízos sociais. Cabe à escola a tarefa de "re/des/construir valores e julgamentos morais atribuídos pelo senso comum às minorias, às diferenças e aos diversos modos de estar no mundo" (FONTES, 2009, p. 99). O re/conhecimento e a valorização da presença, nesse espaço, de alunos LGBTQIA seria a primeira estratégia na conquista do reconhecimento desses sujeitos (OLIVEIRA JÚNIOR; MAIO, 2014).

No entanto, o que sabemos é exatamente o contrário, uma vez que o debate acerca da diversidade sexual parece inexistir no espaço escolar, pois, ao estabelecer uma primeira categoria de análise, observamos determinados interditos presentes no contexto escolar, tais como: os tabus acerca da diversidade sexual, a invisibilidade de estudantes LGBTQIA, as 
implicações da pedagogia do insulto na vida escolar desses alunos e os reiterados processos de "ridicularização" aos quais são expostos.

Baseado nos relatos dos participantes, o interdito enunciador sobre a sexualidade e a diversidade sexual é caracterizado pelo temor de se tocar em um assunto que não se pode ou não se deve falar, que é proibido, considerado tabu, conforme se observa nos trechos a seguir:

"A sexualidade sempre foi um tabu nos espaços de escolarização que eu passei (Participante 03).

"A escola nunca esteve preparada para lidar com nenhum tema polêmico ou [...] Na época da escola esse tema ainda envolvia muito tabu, não se falava sobre, apenas indiferença" (Participante 34).

"Era tabu quando estudava, não era conversado, para a escola isso não existia" (Participante 55).

"A sexualidade sempre foi tabu dentro da maior parte das escolas que estive" (Participante 57).

"Nunca houve discussão ou qualquer tipo de apoio em relação à sexualidade durante o processo escolar" (Participante 108).

Esses dados revelam que, mesmo educadores convivendo cotidianamente com alunos LGBTQIA, recusam-se, possuem dificuldades ou até desconhecem maneiras apropriadas de abordar a discussão diante de situações que demandam uma atuação proativa. É perceptível que profissionais da educação "[...] com distintas bagagens e modos de ver e viver o mundo não estão atrelados a uma perspectiva [...] do exercício da sexualidade" (ABRAMOVAY, 2009, p. 196), tampouco assumem o papel de promover a cultura do respeito para com as diferenças (OLIVEIRA JÚNIOR, MAIO, 2014).

A falta de diálogo cria uma atmosfera de invisibilidade em torno da comunidade LGBTQIA, que parece não existir. Oliveira Jr (2013) reafirma essa proposição em pesquisa realizada com 38 educadores, dentre diretores, pedagogos e professoras em 13 escolas públicas de Ensino Médio no Norte do Paraná, onde analisou as estratégias discursivas empregadas por educadores diante das medidas de promoção do reconhecimento da diversidade sexual. O autor concluiu que a LGBTQIAfobia é reforçada na/pela escola por meio da reiteração de práticas excludentes, ou seja, quando o assunto não é visto, ouvido ou falado, o que evidencia um ocultamento da existência desses alunos, conforme se observa nos trechos:

"Não vi nenhum professor falar abertamente sobre esse assunto. Vivia em constate medo" (Participante 02). 
"O papel da escola na época em que eu estava no ensino fundamental e médio era fingir que questões como identidade de gênero e orientação sexual não existem, ou mais, que são totalmente aquém ou impossíveis de serem abordadas na escola" (Participante 16).

"Vejo que professores e outras pessoas de instituições de ensino preferem fingir que não estamos ali, no caso é uma forma de não nos dar o devido espaço para que aja um respeito de colegas ou de pessoas do convivio" (Participante 21).

"[...] a professora de história finge não existir gays, tanto que pulava partes do livro sobre homossexuais, a maioria dos professores não fala sobre homossexualidade abertamente, tratam como algo que não existe" (Participante 48).

Evidentemente, esses profissionais parecem não “[...] se mostrar dispostos a fazer um diálogo mais aprofundado ou a adotar medidas que favoreçam o avanço dos direitos sexuais [...]” (JUNQUEIRA, 2009, p. 173) e, portanto, não conseguem educar nem a si e nem aos demais estudantes, a fim de que possam lidar com as diferentes manifestações da sexualidade, como se observa nos próprios relatos:

"[...] Poucos foram os profissionais elou colegas que trataram de forma respeitosa e sem ignorar a dor ou a violência ou tratá-la de forma real e atenciosa" (Participante 03).

"Até hoje não sei dizer qual o posicionamento de meus professores em relação à homossexualidade - que dirá a transexualidade, pois, essa palavra, não me recordo nem de ter escutado na escola" (Participante 17).

"Na escola, em nenhum momento, o professor interferiu nessas formas de discriminação, mesmo quando era na presença dele" (Participante 115).

Não é difícil observarmos as consequências da pedagogia do insulto na vida escolar e pessoal de estudantes LGBTQIA, registradas na fala dos entrevistados:

"Os professores ignoravam minha dor e dos meus irmãos gays e trans [...] Uma colega trans saiu também do colegial logo quando abandonei a escola. Antes tive depressão" (Participante 12).

"Se a escola fosse mais acolhedora, minha sexualidade fluiria com maior naturalidade, $e$ minhas vivências escolares seriam melhores, mais saudáveis" (Participante 94).

"[...] uma professora me expôs em frente à classe, em decorrência tive um período de depressão que durou por muito tempo" (Participante 40).

"Por conta da dificuldade que tive de sobreviver na escola tenho marcas profundas na minha vida social e acadêmica" (Participante 47).

"Eu tinha um amigo [...] sofreu muitos preconceitos. As pedagogas nunca souberam lidar com a situação [...] jamais intercederam por ele, sofreu até o último ano do ensino médio, até que foi embora (Participante 71).

"O espaço escolar foi traumático e violento em toda minha vida. Fiquei mais de dez anos longe da escola" (Participante 81).

Os efeitos danosos desse processo tendem a acarretar graves danos pessoais, sociais e formativos, uma vez que o alheamento por parte da escola sobre a (re)produção das diferenças 
tende a gerar uma hierarquia que exclui do convívio diário aqueles que transgridem identidades fixas, além de desestimular a permanência desses alunos por meio da expulsão compulsória (HALL, 2006, SILVA, 2007).

Esse fenômeno atinge inúmeras pessoas em idade escolar e ganha ênfase na vida de indivíduos LGBTQIA, ao gerar,

[...] mal-estar, insegurança, angústia, isolamento e sofrimento. Esses sentimentos podem interferir em suas relações sociais; prejudicar seu rendimento escolar, levandoas até a sair da escola; impedir seu acesso a oportunidades de emprego ou promoção no ambiente de trabalho; aumentar sua vulnerabilidade às DST/HIV/AIDS e ao uso de drogas, e influenciar em sua qualidade de vida e de saúde (BRASIL, 2011, p. 22).

A ausência de intervenção e a falta de reconhecimento da existência de alunos

LGBTQIA evidencia um silenciamento com o propósito de interditá-los, assim:

Supõe-se que essa interdição tome três formas: afirmar que não é permitido, impedir que se diga, negar que exista. [...] de tal maneira que cada um seja, ao mesmo tempo, princípio e efeito do outro: do que é interdito não se deve falar até ser anulado no real; o que é inexistente não tem direito a manifestação nenhuma, mesmo na ordem da palavra que enuncia sua inexistência; e o que deve ser calado encontra-se banido do real como o interdito por excelência (FOUCAULT, 1999, p. 82).

A negação da existência desses alunos "no espaço legitimado da sala de aula acaba por confiná-los às 'gozações' e aos 'insultos' [...] fazendo com que, deste modo, jovens gays e lésbicas só possam se reconhecer como desviantes, indesejados ou ridículos" (LOURO, 1997, p. 68). Endossam as palavras do teórico, os relatos dos participantes da pesquisa:

"Sofri bullying toda vida escolar e a escola fazia de conta que era normal eu sofrer, pois eu era um estudante gay" (Participante 08).

"Piadas homofóbicas durante todo o ensino médio, especialmente por parte de professores homens" (Participante 10).

"Professores me trataram de forma diferente, usando-me como chacota para os colegas" (Participante 21).

"Muitas piadas e agressões verbais "veladas" por parte dos outros alunos. Dois professores me constrangeram" (Participante 34).

"Piadas sobre gays e quem parecesse gay era uma piada comum na escola e é claro que todos olhavam e riam em minha direção" (Participante 37).

"Sempre fui vítima de piadinhas, pegadinhas e afins [...] professor sempre zoava 'viadinhos' e se vangloriava de atitudes extremamente preconceituosas" (Participante 85).

"Presenciei muito a LGBTfobia em forma de piadas, xingamentos, etc." (Participante 94).

"Ouvia pelos corredores piadinhas, mas não havia essa tal interferência, eu sofria calado, medo de usar a palavra gay e ser mais chacota, ouviu e fingia não ouvir e engolia seco" (Participante 95).

"As pessoas que eram homossexuais eram excluídas, motivo de piada e eu não queria passar por isso" (Participante 102). 
"No ensino médio eu fui aliciado por um professor, ele percebeu minha homossexualidade e se aproveitou da situação" (Participante 104).

Esse arsenal de estratégias não tem outra função senão afirmar a existência da "norma", excluindo assim os comportamentos tidos como in/desejáveis (HALL, 2006, SILVA, 2007). Admitida pela escola, essa atitude abusiva também pode se manifestar em forma de "brincadeira" que

[...] inclui ações e palavras para desqualificar, ridicularizar, fazer zombarias, injúrias, insultos, usar mal ou inconveniente de qualquer situação de superioridade de que se desfruta e exceder-se em limites que ultrapassam o respeito ao outro. Neste sentido, inclui agressões que, mesmo não ferindo o corpo, ferem a sensibilidade, as emoções [...] e desrespeitam a identidade e a singularidade da pessoa atingida, podendo causar transtornos ou desconfortos emocionais, que podem traduzir-se em subalternidade [...] (CAETANO, 2008, p. 165).

Sendo assim, não seria um erro afirmar que a escola é uma instituição disciplinadora e normalizadora, onde a diferença, ou tudo aquilo que transgrida a norma, em especial, a norma sexual, é intolerável, tornando-a um lugar de opressão, no qual sujeitos LGBTQIA são expostos a situações de vulnerabilidade elencadas na próxima categoria de análise, à qual fazemos referência à LGBTQIAfobia e alguns de seus desdobramentos, como a violência sistêmica e a vigilância dos corpos.

\section{A LGBTQIAfobia e seus desdobramentos}

A LGBTQIAfobia é um subproduto do modo de pensar e (re)agir das pessoas e "embora seu primeiro elemento seja associado ao ódio, medo, nojo, raiva, desconforto, aversão a pessoas LGBTQIA, por suas condições e posições, ela não pode ser reduzida unicamente a isso" (OLIVEIRA JÚNIOR, MAIO, 2014, p. 79). Para Borrilo (2009, p. 15), “[...] ela é uma manifestação arbitrária que consiste em qualificar o outro como contrário, inferior ou anormal”, promovendo desigualdades ou prejuízos para as partes desqualificadas.

Nesse sentido, essa estratégia disciplinadora implica em "[...] constituir pares de representação de valores opostos, instaurar diferenças quantitativas entre as forças em questão, estabelecer um jogo de sinais-obstáculos que possam submeter o movimento das forças a uma relação de poder" (FOUCAULT, 2004, p. 87).

Esses atos de violência podem acontecer de modo menos ou mais sutil, como xingamentos, exclusão, discriminação e preconceito, podendo ainda se desdobrar em atitudes piores, tais como agressões físicas e tentativas de homicídio, como relataram os participantes da pesquisa: 
"Na sexta série, numa aula de Educação Física [...] um professor me chamou de gay dentro de uma sala de aula com quase 40 alunos, tendo eu apenas 12 anos" (Participante 08).

"Um cara da biblioteca disse que mataria homossexuais (funcionário da escola). [...] Um colega tentou me jogar da ponte uma vez" (Participante 12).

"Além dos xingamentos, levei murro e pedrada dentro da escola mais de uma vez e ninguém foi responsabilizado, mesmo quando eu levava o assunto até à diretoria" (Participante 16).

"Surras na saída da escola, perseguições a pé e humilhações eram constantes, bem como agressões sexuais" (Participante 37).

"[...] mesmo coordenadores ou diretores das instituições olhavam pra certos meninos $e$ falavam baixo 'boiolinha'”' (Participante 44).

"Casos de homofobia não eram levados a sério pela orientação, quando chegava à violência física era tratado como briga entre os dois (as duas) alunos (as), sendo relatado somente o contato físico" (Participante 69).

"Desde o primeiro momento dentro da escola fui hostilizada, agredida, excluída dos espaços [...] antes de conseguir completar a quarta série, fui vítima de abuso sexual no banheiro masculino e expulsa da escola" (Participante 70).

"Já sofri muito preconceito de professores e funcionários" (Participante 78).

"Eu era agredido todos os dias e a minha autoestima era inexistente [...] Professores diziam com frequência que ser gay era uma das piores coisas que podia lhe acontecer. Foi dito uma vez, em tom de piada, que a única coisa pior que morrer era virar "viado" (Participante 97).

"Fui agredido verbalmente e fisicamente por outros alunos" (Participante 101).

A violência sistêmica "[...] não tem outro papel, sejam quais forem as técnicas empregadas, senão o de dizer enfim o que estava articulado silenciosamente no texto primeiro" (FOUCAULT, 2007, p. 25). A reafirmação e a negativação às quais alunos LGBTQIA são submetidos no espaço escolar por seus "colegas" é reiterada pelo discurso de professores e professoras ao minimizar/ridicularizar os efeitos ulteriores dessa antilocução ou esquiva. Ela adquire força na necessidade constante de impor qual sexualidade deve ser dominante, a heterossexual, e todos aqueles que não se enquadram nessa norma são considerados "desviantes", "pervertidos", “doentes", "bizarros", esquema fundador do preconceito e da discriminação contra sujeitos LGBTQIA.

Outro desdobramento da LGBTQIAfobia consiste na "vigilância dos corpos", expressão cunhada por Foucault (2004). Os depoimentos coletados nesta pesquisa evidenciam que a escola é uma instituição fortemente empenhada na reafirmação da heterossexualidade, colocando sob vigilância os corpos de todos, desde a mais precoce idade, conforme se evidencia nos trechos a seguir: 
"A homossexualidade é tratada como um erro desde a educação infantil" (Participante $44)$.

"Ainda no jardim de infância, eu ouvi o primeiro insulto homofóbico. Alguns garotos se referiram a mim de modo pejorativo. Eu não entendia o que havia de errado comigo na opinião deles, mas me senti totalmente deslocado. A experiência foi tão ruim que eu nunca mais esqueci" (Participante 64).

"As outras crianças me apontaram como gay antes mesmo de saber o que era isso" (Participante 97).

Salva e Stimamiglio (2011) reiteram que a criança na Educação Infantil desconhece as práticas e táticas culturais que sinalizam a diferença por meio do arcabouço sociocultural empregado na construção da sexualidade. Algo que aos poucos será vigiado, corrigido e punido “[...] sobre o corpo que precisa ser esculpido, enquadrado, domesticado, resguardado, produzindo identidades não apenas demarcadas pelas diferenças, mas também pela hierarquia" (p. 1363).

“O modo como alunos e alunas devem se comportar é correspondente a um laborioso aprendizado sociocultural que os ensina a agir conforme as prescrições de cada gênero. Há uma expectativa em relação à maneira de como alunos devam se portar" (OLIVEIRA JÚNIOR; MAIO, 2014, p. 81). Conforme o gênero, definido pela sociedade, há a inculcação de modos específicos de como essas pessoas deverão estudar, relacionar-se com outras pessoas, reproduzir as maneiras de ser homem e mulher, constituindo a escola num agente de re/des/construção de estereótipos de gênero. Esse é o foco de nossa terceira categoria de análise, que se encontra organizada em três vertentes: a constituição da identidade de gênero, o "heteroterrorismo" e a masculinidade frágil.

\section{$6 \mathrm{Re} / \mathrm{Des} /$ Construindo estereótipos de gênero}

A construção histórica, cultural, social e política sobre as diversas possibilidades de ser feminino e/ou masculino ultrapassa o "ser macho" ou "ser fêmea", enfatizando diferentes papéis e comportamentos adequados a homens e mulheres por meio de referenciais, tanto estruturais quanto ideológicos, cuja consequência é a distribuição desigual do poder e das oportunidades, a partir daquilo que se define como sendo "coisa de homem" e "coisa de mulher" (OLIVEIRA JÚNIOR, 2013).

Tais aspectos implicam diretamente no modo como as pessoas se comportam. Há uma expectativa social em relação à maneira como “[...] homens e mulheres devem andar, falar, sentar, mostrar seu corpo, brincar, dançar, namorar, cuidar do outro, amar, trabalhar, gerenciar 
outras pessoas, ensinar, dirigir o carro, gastar o dinheiro, ingerir bebidas, dentre outras atividades" (BRASIL, 2009, p. 40).

No entanto, a identidade de gênero não é algo dado, e sim, constituído e vivenciado ativamente por cada homem e mulher a partir dos elementos fornecidos por sua cultura, ou pelo fato de alguém se sentir masculino e/ou feminino, num processo contínuo e dinâmico, não dado no nascimento e a partir daí marcado para sempre. Ou seja, trata-se de uma construção cultural/social e histórica, uma aquisição, uma performance, uma atuação (BUTLER, 2009).

Nesse sentido, podemos dizer que fazer-se homem ou mulher depende de escolhas “[...] das marcas, dos gestos, dos comportamentos, das preferências e dos desgostos que lhes são ensinados e reiterados, cotidianamente, conforme normas e valores de uma dada cultura" (LOURO, 2008, p. 17).

Portanto, a forma como o indivíduo percebe sua

[...] identidade de gênero inclui o senso pessoal do corpo, no qual podem ser realizadas, por livre escolha, modificações estéticas ou anatômicas por meios médicos, cirúrgicos ou outros. Lembremos, em especial, das pessoas transexuais masculinas e femininas e das travestis. Mas todos nós temos nossa identidade de gênero, pois trata-se da forma que nos vemos e queremos ser vistos, reconhecidos e respeitados, como homens ou como mulheres (JESUS, et all.,, 2008, p. 16).

Esse processo de construção da identidade de gênero não é livre de influências, já que sofre interferências das mais distintas instituições sociais. A escola, sendo uma delas, apresenta uma tendência a "[...] delimitar espaços servindo-se de símbolos e códigos, ela afirma o que cada um pode (ou não pode) fazer, ela separa e institui. Informa o 'lugar' dos pequenos e dos grandes, dos meninos e das meninas" (LOURO, 1997, p. 58).

Nesse sentido, quando estudantes, intencionalmente ou não, misturam "[...] os dois mundos (o masculino e o feminino)", tais ações "são interpretadas pelo olhar atencioso das instituições escolares como um indicador de uma homossexualidade latente" (BENTO, 2011, p. 552). Por conseguinte, a violência e a exclusão podem ser manifestas em forma de “[...] piadas e gozações, apelidos e gestos para se dirigirem àqueles e àquelas que não se ajustam aos padrões de gênero e sexualidade admitidos na cultura que vivem" (LOURO, 2010, p. 28), conforme relatos dos participantes da pesquisa:

"[...] as crianças enxergavam quaisquer características de estereótipos que em seu entendimento indicavam homossexualidade como motivo de chacota e razão para se tirar sarro e diminuir aquela pessoa, ou mesmo se afastar dela" (Participante 17).

[...] "Durante o segundo ano do Ensino Médio um aluno foi perseguido por um professor por ser afeminado" (Participante 47). 
"[...] sempre fui alvo de brincadeiras e xingamentos de outros alunos por ser afeminado. Inclusive, dois professores, [...] sempre faziam piadas para ridicularizar os homossexuais, e sempre olhavam diretamente para mim ao contar estas piadas" (Participante 59).

"Sempre fui vista como alguém com problemas emocionais e um péssimo exemplo pra outras meninas. Havia o cuidado de não deixar outras meninas ao meu lado porque eu poderia 'levá-las' para o mau caminho" (Participante 105).

"[...] sentia que marcas corporais já despontavam trazendo regulações para meu corpo" (Participante 110).

"Eu tinha um amigo muito educado na minha sala de aula, ele era diferente dos outros meninos, sempre nos tratava muito bem, não tinha a dita 'masculinidade' que muitos exigem dos homens, ele era tímido, [...]... E por esse jeito dele, falavam que era afeminado" (Participante 71).

“[...] tive muitas dificuldades em fazer amizades, pelo fato de não ser bem aceito pelos meninos" (Participante 100).

Alunos LGBTQIA são cotidianamente surpreendidos por essa violência, que tende a causar efeitos de duas maneiras: "a primeira delas é a vitimização direta, ou seja, a dor da agressão, de ter sido ofendido por um colega de escola (OLIVEIRA JÚNIOR; MAIO, 2014, p. 84). Já a segunda é “[...] aquela realizada pela exposição que a situação de violência implica. A vergonha do constrangimento sofrido na frente de outros alunos, professores, ou mesmo na frente dos pais tem um alto potencial destrutivo" (GÓIS; SOLIVA, 2011, p. 42).

Oliveira Júnior e Maio (2014, p. 84) sublinham que "os resultados dessas humilhações são tão letais quanto a própria violência física, já que suas ações têm como princípio afetar a valorização pessoal, a autoconfiança e a confiança no outro, a começar pela imparcialidade do educador diante dessa situação".

Esses sentimentos são experienciados, ao longo de todo o processo de escolarização, tanto pelas alunas quanto pelos alunos; no entanto, parece ter um peso maior quando pensamos na construção da identidade masculina, pois diz respeito a como ser homem e portar-se como macho, marcando "brincadeiras" entre meninos pela violência, enquanto as brincadeiras entre meninas e mulheres se destacam pela presença da cordialidade. "Isso, de um lado, faz pensar na vigilância obsessiva das normas de gênero na construção e no disciplinamento dos sujeitos portadores da identidade de referência, a masculina heterossexual [...]" (JUNQUEIRA, 2012, p. 77), visto que sobre os meninos essa fiscalização é intensificada por um processo definido por Bento (2011) como "heteroterrorismo", conforme relatado:

"Havia muita fiscalização e regulação entre os meninos sobre o que é ser homem e dali vinha todo o terror" (Participante 28).

"Na escola sempre sofri bullying [...] por não ser tão homenzinho quanto meus amigos, sempre ouvia 'fala igual homem', o que colaborou para aumentar minha timidez e escassez de falas" (Participante 53). 
"Muito cedo, os meninos começaram a zombar e a se afastar de mim. Às vezes, brincava com as meninas, mas a maior parte do tempo eu ficava só. Detestava ir à escola" (Participante 97).

"Os meninos me chamavam de viadinho e isso me causou susto e medo. O sentimento era de não querer vivenciar a discriminação e comecei a me distanciar de tudo que era associado à homossexualidade e fortaleci aspectos masculinos na minha constituição" (Participante 115).

Com base nesses relatos, percebemos que a construção da identidade heterossexual busca se solidificar em condutas que visam reforcá-la. Sendo assim, fortalecer a homofobia "[...] é um mecanismo essencial do caráter masculino, porque ela permite recalcar o medo enrustido do desejo homossexual" (BORRILO, 2010, p. 89).

Junqueira (2012, p. 67-68) percebe essa arbitrariedade

[...] como um fenômeno social relacionado a preconceitos, discriminação e violência voltados contra quaisquer sujeitos, expressões e estilos de vida que indiquem transgressão ou dissintonia em relação às normas de gênero, à matriz heterossexual, à heteronormatividade. E mais: seus dispositivos atuam capilarmente em processos heteronormalizadores de vigilância, controle, classificação, correção, ajustamento e marginalização com os quais todos/as somos permanentemente levados/as a nos confrontar.

Outro aspecto da violência de gênero refere-se ao medo de qualquer possibilidade de aproximação afetiva/sexual de pessoas LGBTQIA com aqueles que se reconhecem heterossexuais. No entanto, como dito anteriormente, quando essa aproximação ocorre entre meninas, destaca-se o campo da afetividade e não da violência, conforme relato de uma participante da pesquisa:

"Quando adolescente a homossexualidade minha já aparecia: eu mandei um bilhete para uma colega dizendo que a amava. Ela 'naturalmente' se queixou com a professora que ficou meio sem ação. Enfim, tudo foi tratado como indisciplina" (Participante 80).

Porém, quando essa aproximação se dá entre meninos, na maioria das vezes os mesmos demonstram enfaticamente aversão às "cantadas" vindas de homossexuais, sentem-se ameaçados em sua masculinidade e, muitas vezes, reagem com violência.

"[...] os meninos sempre me batiam sem eu sequer olhar para eles. Lembro de uma vez que eu tinha cerca de 10 anos e ganhei um soco na boca na saída da escola porque disse para uma amiguinha que eu gostava de um menino da minha sala. Esse menino ficou sabendo disso no mesmo dia e me bateu com outros 9 garotos" (Participante 15).

O medo de qualquer aproximação física ou emocional entre meninos está “[...] relacionado ao medo da atração ao corpo do outro, já que isso rompe com os códigos presentes no ritual performático da masculinidade" (SILVA, 2008, p. 15). Essa afirmação é comprovada 
em uma pesquisa realizada por Abramovay, Castro e Silva, em que muitos indivíduos alegam não ter preconceito, “[...] desde que o homossexual permaneça longe, não se aproxime e, principalmente, que não insinue que eles possam ser um igual ou um parceiro da relação" (2004, p. 280).

Diante dos dados aqui analisados, percebemos que a escola, que teoricamente deveria ser um espaço de promoção dos direitos elementares, é vista como um local de sofrimento, de violência e ataque cotidiano à autoestima de estudantes LGBTQIA, reproduzindo e ratificando as diferenças. Assim, enquanto instituição social, ela parece não saber ou se esquece de que seus atos, discursos ou mesmo a ausência deles são ferramentas utilizadas no extermínio de direitos, que, em seus múltiplos desdobramentos, podem abortar quaisquer possibilidades de conquistas materiais e sociais futuras por parte dos estudantes LGBTQIA, destituindo-lhes as esperanças e expectativas de vida.

\section{Considerações finais}

Podemos assegurar que conseguimos alcançar o objetivo desta pesquisa, que consistia em analisar os relatos das vivências escolares de pessoas LGBTQIA, tendo como metodologia a análise de conteúdo. Este estudo apresentou dados pertinentes ao objetivo traçado e evidenciou a necessidade de elaborar novas reflexões sobre o tema. Portanto, discussões como essa não devem se encerrar aqui, pelo contrário, uma série de ações pode ser pensada de modo a preencher lacunas no que se refere à discussão da temática sexualidade e identidade de gênero, tendo em vista sua complexidade, necessidade de atenção e investigação.

Depreendemos, a partir das análises dos dados coletados, que as causas da LGBTQIAfobia são reforçadas na/pela escola, influenciadas diretamente pela segregação ou indiretamente na omissão do debate sobre a diversidade sexual e o gênero, bem como pelas variadas formas de assédio, impostas a alunos LGBTQIA. Os padrões normalizadores adotados pela escola provocam a exclusão daqueles tidos como diferentes. Os "regimes de verdades estipulam que determinadas expressões relacionadas com o gênero [e manifestações da sexualidade] são falsas, enquanto outras são verdadeiras e originais, condenando a uma morte em vida, exilando em si mesmos os sujeitos que não se ajustam às idealizações” (BENTO, 2011, p. 553).

A LGBTQIAfobia impacta diretamente nos sentimentos, na dignidade e no desempenho escolar. As agressões físicas e verbais, interiorização, exclusão ou repressão destituem a esperança de sobrevivência digna e segura das pessoas LGBTQIA; “criam situações 
tristes de constrangimentos, sofrimento psíquico intenso, além de impulsionar sua saída da escola" (OLIVEIRA JÚNIOR; MAIO, 2014, p. 78). Tais fenômenos causam solidão, rejeição, resistência de pertença, sujeição, desproteção e insegurança nas pessoas LGBTQIA em relação aos outros. Os efeitos sociais desse processo incidem na vivência negativa da sexualidade, internalização da frustração, humilhação, vergonha, medo, dúvida e baixa autoestima.

Enquanto estudiosos dessa temática, precisamos fornecer subsídios para que a comunidade escolar coloque seus sentidos a postos e perceba as distintas maneiras de apresentar a sexualidade como algo positivo, defendendo o respeito a todos indistintamente. Nesse sentido, propomos algumas possíveis estratégias de enfrentamento à LGBTQIAfobia, como a capacitação de professores, o desenvolvimento e a oferta de materiais didáticos que subsidiem a atuação em sala de aula; a discussão da diversidade sexual em livros didáticos; a realização de encontros pedagógicos e eventos cujas discussões façam parte; a inclusão de conteúdos sobre gênero e diversidade sexual no projeto escolar; o debate da escola com as demais esferas sociais, como a saúde e a assistência social, sobre ações e propostas de enfrentamento à LGBTQIAfobia; políticas assistenciais e de saúde para alunos LGBTQIA em situação de vulnerabilidade; atendimento psicossocial a alunos expostos às distintas violências por orientação sexual; dentre outras.

Finalizamos as discussões aqui apresentadas reafirmando a necessidade de dar voz às vivências escolares de pessoas LGBTQIA, pois é ouvindo-as que podemos pensar na ampliação dessas estratégias de combate e enfrentamento às distintas táticas subversivas a que são submetidas na escola, pois, como reafirmou o Participante 84 dessa pesquisa: “[...] Com toda a certeza é um assunto que precisa ser debatido com a maior seriedade e comprometimento possível, já que vencer àqueles que nos veem com maus olhos é uma tarefa bastante árdua”.

\section{Referências}

ABRAMOVAY, Miriam (Coord.). Revelando tramas, descobrindo segredos: violência e convivência nas escolas. Brasília: Rede de Informação Tecnológica Latino-Americana RITLA, Secretaria de Estado de Educação do Distrito Federal - SEEDF, 2009.

BARDIN, Laurence. Análise de Conteúdo. Tradução: Luís Antero Reto e Augusto Pinheiro. São Paulo: Edições 70, 2016.

BENTO, Berenice. Na escola se aprende que a diferença faz a diferença. Estudos Feministas, Florianópolis, mai./ago. 2011, p. 549-559. 
BORRILO, Daniel. A. Homofobia. In: LIONÇO, Tatiana; DINIZ, Débora (Org.). Homofobia \& Educação: um desafio ao silêncio. Brasília: Letras Livres: EdUnB, 2009, p. 15-46.

BORRILO, Daniel. A. Homofobia: história e crítica de um preconceito. Tradução: Guilherme João de Freitas Teixeira. Belo Horizonte: Autêntica, 2010.

BRASIL. Gênero e diversidade na escola: formação de professoras/es em Gênero, Orientação Sexual e Relações Étnico-Raciais. Livro de conteúdo. v.1, versão 2009. Rio de Janeiro: CEPESC; Brasília: SPM, 2009.

BRASIL. Ministério da Saúde, Secretaria de Vigilância em Saúde. Departamento de DST, AIDS e Hepatites Virais. Adolescentes e jovens para uma educação entre pares: diversidades sexuais. Brasília: Ministério da Saúde, v. 8, 2011.

BUTLER, Judith. Corpos que pesam: sobre os limites discursivos do "sexo". In: LOURO, Guacira Lopes (Org.). O corpo educado. Tradução: Tomaz Tadeu da Silva. 3. ed. Belo Horizonte: Autêntica, 2009, p. 151-172.

CAETANO, Márcio Rodrigo Vale. Rompendo fronteiras e problematizando as diferenças sexuais. In: RIBEIRO, Paula Regina Costa. SILVA, Fabiana Ferreira da. MAGALHÃES, Joanalira Corpes. QUADRADO, Raquel Pereira (Orgs.). Educação e Sexualidade: identidades, famílias, diversidade sexual, prazeres, desejos, preconceitos, homofobia...Rio Grande: Editora da FURG, 2008, p. 158-171.

FOUCAULT, Michel. A ordem do discurso. 15. ed. São Paulo: Loyola, 2007.

FOUCAULT, Michel. História da sexualidade 1: a vontade de saber. Tradução: Maria Thereza da Costa Albuquerque e J. A. Guilhon Albuquerque. 13. ed. Rio de Janeiro: Graal, 1999.

FOUCAULT, Michel. Vigiar e punir: nascimento da prisão. Tradução: Raquel Ramalhete. 29 ed. Petrópolis/RJ: Vozes, 2004.

FONTES, Malu. Ilustrações do silêncio e da negação. In: LIONÇO, Tatiana. DINIZ, Debora (Org.). Homofobia \& Educação: um desafio ao silêncio.

Brasília: Letras Livres: EdUnB, 2009, p. 99 - 114.

HALL, Stuart. A Identidade Cultural na Pós Modernidade. Tradução: Tomaz Tadeu da Silva; Guacira Lopes Louro. 11. ed. Rio de Janeiro, RJ: DP\&A, 2006.

JESUS, Beto de. RAMIRES, Lula. UNBEHAUM, Sandra. CAVASIN, Sylvia. Diversidade Sexual na Escola: uma metodologia de trabalho com adolescentes e jovens. São Paulo: Ecos, Corsa, 2008.

JUNQUEIRA, Rogério Diniz. “Aqui não temos gays nem lésbicas”: estratégias discursivas de agentes públicos ante medidas de promoção do reconhecimento da diversidade sexual nas escolas. Bagoas. n. 04, p.171-190, 2009. 
JUNQUEIRA, Rogério Diniz. A Pedagogia do Armário: heterossexismo e vigilância de gênero no cotidiano escolar. Revista Educação On-line PUC, Rio de Janeiro, n. 10, p. 64-83, 2012.

JUNQUEIRA, Rogério Diniz. Pedagogia do armário: a normatividade em ação. Revista Retratos da Escola, Brasília, v. 7, n. 13, p. 481-498, jul./dez. 2013.

LOURO, Guacira Lopes. Gênero e sexualidade: pedagogias contemporâneas. Pro-Posições, v. 19, n. 2 (56) - mai./ago. 2008, p. 17-23.

LOURO, Guacira Lopes. Gênero, sexualidade e educação. Uma perspectiva pósestruturalista. Petrópolis/RJ: Vozes, 1997.

LOURO, Guacira Lopes. Pedagogias da sexualidade. In: LOURO, Guacira (Org.). SILVA, Tomaz Tadeu da (Trad.). O corpo educado. 3. ed. Belo Horizonte: Autêntica, 2010, p. 07-35.

OLIVEIRA JÚNIOR, Isaias Batista de. MAIO, Eliane Rose. Homofobia e (re)produção da(s) diferença(s): ações conjugadas no plural no contexto escolar. Momento, v. 23, n. 2, p. 73-94, jul./dez. 2014.

OLIVEIRA JÚNIOR, Isaias Batista de. MAIO, Eliane Rose. O/a diretor/a não viu, a pedagoga não ouviu e a professora não quer falar: discursos docentes sobre diversidade sexual, homofobia e "Kit Gay". 2013. 260 f. Dissertação de Mestrado. Universidade estadual de Maringá. Maringá, 2013.

SALVA, Sueli. STIMAMIGLIO, Neusa Maria Roveda. Ser menino e ser menina também se aprende na escola. In: Seminário Corpo, gênero e sexualidade: instâncias e práticas de produção nas políticas da própria vida. Anais... Rio Grande, 2011, p. 1361 - 1370.

SILVA, Joseli Maria. A cidade dos corpos transgressores da heteronormatividade. Geo UERJ, n. 18, vol. 1, 2008, p. 01-17.

SILVA, Tomaz Tadeu da. A produção social da identidade e da diferença. In: SILVA, Tomaz Tadeu da (Org.). Identidade e Diferença: a Perspectiva dos Estudos Culturais. 7. ed. Petrópolis/RJ: Vozes, 2007, p. 73-102.

YOUNG, Iris Marion. Five Faces of Oppression. In: HENDERSON, George, WATERSTONE, Marvin (Ed.). Geographic Thought: a praxis perspective. New York: Routledge. 2009, p. 55-71. 